\title{
Editorial
}

\section{Tell me, i will forget. Show me, i may remember. But involve me i will understand.}

\section{Rabii Noomene}

Writing academic papers is one of the most important factors in the assessment of junior's career progression. Some fortunate trainees working in academic research centers engage easily in substantial original big studies. However, the majority of trainees are struggling to have such opportunities.

Juniors doctors usually coauthor publications with senior colleagues. Sometimes they perform all the job. They review the literature; collect the data; and write the manuscript. But their final citation is not always fair. That is why we still believe that non research publications such as reviews; opinions; and case reports are more suitable for beginners. These instructive experiences allow them to challenge the publishing process and let them meet the final taste of their effort.

Since their appearance in the 1700s, the number of scientific journals has grown beyond the imagination especially with the advent of electronic publishing. This improved the access to the information and offered an easy 'up to date' to all junior researchers.

Unfortunately, the medical publishing is no that immune to fakery. The number illegitimate and carnivore journals is still considerable. Pseudoscience proliferated wildly during last years and some publishers presumably contributed to it. Young researchers and trainee doctors are the ideal victims. This may be due to the lack of experience; but most of the time to their big motivation to be involved in academic writing. That may better involve a system thinking supervisor- ship to bring out the truth from the falsehood.

Scientific writing is not transforming data to sentences; it is an art. We believe that the necessary skills can be acquired early in the research career. Juniors are the future generation of writers who will uphold the truth. We will try to give them the opportunity. Welcome to junior medical research... 